\title{
Physical aging of glassy perfluoropolymers in thin film composite membranes. Part I. Gas transport properties
}

\author{
Milad Yavari, Tho Le, Haiqing Lin ${ }^{*}$ \\ Department of Chemical and Biological Engineering, University at Buffalo, \\ The State University of New York, Buffalo, NY 14260, U.S.A.
}

*Corresponding author. Tel: +1-716-645-1856, fax: +1-716-645-3822

Email: haiqingl@ buffalo.edu

Revised submission to Journal of Membrane Science

June 8, 2016 


\section{ABSTRACT}

Physical aging of thin film glassy polymers continuously decreases gas permeability, presenting a great challenge in designing membrane systems for long-term gas separation. Most studies on the effect of physical aging on membrane applications use freestanding thin films, which are often annealed above the polymer glass transition temperature $\left(T_{g}\right)$ before gas permeability is determined. However, industrial membranes are often thin film composites (TFCs) comprising the thin film on top of porous polymeric supports, and they may not be annealed above the $T_{g}$. The objective of this study is to investigate the effect of physical aging of the selective layer on gas permeance and selectivity of TFC membranes to establish industrial relevance. Two-layer TFC membranes consisting of perfluoropolymers (including Teflon ${ }^{\circledR}$ AF1600 and Hyflon ${ }^{\circledR}$ AD) at various film thicknesses $(50-400 \mathrm{~nm})$ on polyethersulfone porous support were prepared and determined for permeances of $\mathrm{CH}_{4}, \mathrm{~N}_{2}, \mathrm{H}_{2}$ and $\mathrm{CO}_{2}$ at $35{ }^{\circ} \mathrm{C}$ for over $1000 \mathrm{hr}$. Gas permeances decrease with time, and the decrease is more significant for larger penetrants and for membranes with thinner selective layers. For example, $\mathrm{CH}_{4}$ permeance decreases by $54 \%$ and $27 \%$ after aging for about $1400 \mathrm{hr}$ in TFC membranes comprising 50-nmand 370-nm-thick Teflon AF1600, respectively. The decrease of gas permeances over time in these TFC membranes is compared with that of freestanding films. This study is one of only a few to present the results of physical aging in industrial TFC membranes and to provide useful insights for practical membrane applications.

Keywords: Thin film composite (TFC) membranes, Perfluoropolymers, Physical aging, Gas permeance 


\section{Nomenclature}

\begin{tabular}{|c|c|}
\hline$A_{m}$ & membrane area $\left(\mathrm{cm}^{2}\right)$ \\
\hline$A_{A}$ & pre-exponential factor ( $c f$. Eq. 2) \\
\hline$B_{0}$ & an adjustable constant ( $c f$. Eq. 9) \\
\hline$B_{A}$ & a constant related to penetrant size ( $c f$. Eq. 2$)$ \\
\hline$d_{A}$ & kinetic diameter of gas molecule A (nm) \\
\hline$f$ & fractional free volume of a polymer \\
\hline$l$ & thickness of thin films $(\mathrm{cm})$ \\
\hline$N_{A}$ & flux of gas A through membrane $\left(\mathrm{cm}^{3}(\mathrm{STP}) / \mathrm{s}\right)$ \\
\hline$p_{2, A}$ & pressure of gas $\mathrm{A}$ in the membrane upstream $(\mathrm{cmHg})$ \\
\hline$p_{1, A}$ & pressure of gas $\mathrm{A}$ in the membrane permeate $(\mathrm{cmHg})$ \\
\hline$P_{1 h}$ & permeability of a polymer at an aging time of $1 \mathrm{hr}$ \\
\hline$P_{A}$ & permeability of gas A of a polymer (Barrer) \\
\hline$P_{A} / l$ & permeance of gas A in a membrane (GPU) \\
\hline$P_{t}$ & permeability of a polymer at an aging time of $t$ (Barrer) \\
\hline$t$ & time $(\mathrm{hr})$ \\
\hline TFC & thin film composite \\
\hline$T_{g}$ & glass transition temperature $\left({ }^{\circ} \mathrm{C}\right)$ \\
\hline$V$ & specific volume of a polymer $\left(\mathrm{cm}^{3} / \mathrm{g}\right)$ \\
\hline$V_{0}$ & specific occupied volume of a polymer at $0 \mathrm{~K}\left(\mathrm{~cm}^{3} / \mathrm{g}\right)$ \\
\hline
\end{tabular}

Greek letters

$\alpha_{\mathrm{A} / \mathrm{B}} \quad$ permeability selectivity of gas A over B 

$\beta_{t} \quad$ relative permeability at aging time of $t$ to $1 \mathrm{hr}(c f$. Eq. 6)
$\gamma_{A} \quad$ permeance or permeability reduction rate ( $c f$. Eq. 7)
$\kappa$
an adjustable constant in Eq. 9

$\begin{array}{ll}\text { Subscript } & \\ 1 & \text { membrane permeate side } \\ 2 & \text { membrane feed side } \\ A & \text { gas component } A \\ B & \text { gas component } B \\ t & \text { aging time (hr) }\end{array}$




\section{Introduction}

Polymeric membranes have emerged as an important technology for gas separation due to their high energy-efficiency, simplicity in operation and compactness [1-3]. The key to the wide use of membrane systems is high performance polymeric membranes comprising a thin selective layer $(0.1-0.2 \mu \mathrm{m})$ on top of a microporous support. The selective layer is often made of glassy polymers, which governs the gas transport properties such as permeance and selectivity, and the porous support provides mechanical properties needed for practical applications. While the glassy polymer is fabricated to be thinner $(<100 \mathrm{~nm})$ to increase gas permeance and thus lower capital cost, the thin film is usually susceptible to physical aging [4], i.e., gas permeability decreases with time, and the decrease rate is more substantial with thinner films [5-8]. The decrease of permeance over time not only increases the capital cost, but also introduces the complexity in managing the long-term system performance [9].

The decrease of gas permeance with time in thin film polymers has been widely documented for a broad range of glassy polymers such as polysulfone [5-7,10], poly(phenylene oxide) [6,10], $\operatorname{Matrimid}^{\circledR}[6,7,10], 6 F D A-d u r e n e ~[11]$, perfluorocyclobutyl (PFCB) polymers [12], poly(1trimethylsilyl-1-propyne) (PTMSP) [13], and polymers of intrinsic microporosity (PIMs) [8,1316]. The physical aging also increases gas selectivity that benefits from the favorable diffusivity selectivity. The behavior has been interpreted using the free volume model $[4,7,10,17,18]$. Within this framework, glassy polymers are at non-equilibrium state, and polymer chains tend to relax towards equilibrium state, resulting in the reduction of free volume $[19,20]$ and thus gas permeability $[4,10]$. The physical aging has also been shown to affect other properties, such as refractive index [21], glass transition temperature $\left(T_{g}\right)$ [22], dielectric properties, and dynamic mechanical properties $[4,17,23]$. 
The effect of physical aging on gas permeability is often determined in a freestanding thin film. The film is usually annealed above its $T_{g}$ to eliminate the history and then it is moved onto the top of microporous ceramic supports for permeation tests $[6,7,10,21,24-26]$. While such experimental design is critical to explore the fundamental polymer structure/aging property relationship, it remains unclear if the aging behavior of the freestanding films would be indicative to that of the TFC membranes for the three reasons as described below. First, for the TFC membranes, the thin selective layer is often formed by coating the solution on top of a polymeric porous support followed by solvent evaporation. The use of polymer substrates and membrane forming procedures may influence segmental mobility of the thin film and thus its aging behavior. For example, at film thickness of less than $100 \mathrm{~nm}$, poly(methyl methacrylate) (PMMA) shows an increased $T_{g}$ on a silicon oxide surface and a decreased $T_{g}$ on a gold surface [27]. Second, industrial membranes may not be annealed above the $T_{g}$ of the selective layer polymer, since the porous support and paper layer may not sustain the high temperature. Third, the freestanding films typically have a thickness of $400 \mathrm{~nm}$ or greater to ensure that they are defect-free for gas separation. On the other hand, industrial TFC membranes can have the selective layer thinner than $100 \mathrm{~nm}[1,28]$. Therefore, despite the rich literature on the physical aging behavior of freestanding films, there is a critical need to investigate the aging behavior in the TFC membranes.

The permeance decrease with time is often more rapid if the polymer has higher fractional free volume [2]. However, several amorphous glass perfluoropolymers such as Teflon ${ }^{\circledR}$ AF1600 and Hyflon ${ }^{\circledR} \mathrm{AD}$, show a much slower aging rate than hydrocarbon polymers with similar or lower fractional free volume in freestanding films $[13,28,29]$. These perfluoropolymers have high permeability, moderate selectivity and excellent chemical stability and therefore, they have 
been extensively investigated for the separation of $\mathrm{CO}_{2} / \mathrm{CH}_{4}, \mathrm{O}_{2} / \mathrm{N}_{2}, \mathrm{H}_{2} / \mathrm{CH}_{4}, \mathrm{He} / \mathrm{CH}_{4}$ [28-30], and ethanol/water [31].

The objective of this study (Part I and Part II) is to investigate the effect of physical aging of the selective layer on the gas permeance and selectivity of TFC membranes comprising Teflon AF1600 and Hyflon AD. In the present Part I study, industrial two-layer TFC membranes consisting of perfluoropolymer thin films at various thicknesses $(50-400 \mathrm{~nm})$ on polyethersulfone (PES) ultrafiltration support were successfully prepared. Pure-gas permeances of $\mathrm{CH}_{4}, \mathrm{~N}_{2}, \mathrm{H}_{2}$ and $\mathrm{CO}_{2}$ at $35^{\circ} \mathrm{C}$ were measured for over $1000 \mathrm{hr}$. The changes of gas permeances over time in these TFC membranes are compared with those of the freestanding films (including perfluoropolymers and hydrocarbon polymers) reported in the literature. The Part II study will determine the $T_{g}$ of the thin selective layers at various thicknesses and aging time in the TFC membranes, which will be correlated with the changes in the free volume and thus gas permeances.

\section{Background}

TFC membranes often have an unknown selective layer thickness $(l)$ and therefore, gas permeance for component $\mathrm{A}\left(P_{A} / l\right)$ is often used to characterize the membrane performance [32]:

$$
\frac{P_{A}}{l}=\frac{N_{A}}{A_{m}\left(p_{2, A}-p_{1, A}\right)}
$$

where $N_{A}\left[\mathrm{~cm}^{3}(\mathrm{STP}) / \mathrm{s}\right]$ is gas flux through a membrane, $P_{A}\left[\mathrm{~cm}^{3}(\mathrm{STP}) \mathrm{cm} / \mathrm{cm}^{2} \cdot \mathrm{s} \cdot \mathrm{cmHg}\right]$ is gas permeability of the thin film polymer, $A_{m}$ is the membrane area $\left(\mathrm{cm}^{2}\right)$, and $p_{2, A}$ and $p_{1, A}$ are the feed and permeate pressure $(\mathrm{cmHg})$, respectively. Gas permeability is often expressed in units of Barrer, where 1 Barrer $=10^{-10} \mathrm{~cm}^{3}(\mathrm{STP}) \mathrm{cm} / \mathrm{cm}^{2} \cdot \mathrm{s} \cdot \mathrm{cmHg}$, and gas permeance has units of GPU, where $1 \mathrm{GPU}=10^{-6} \mathrm{~cm}^{3}(\mathrm{STP}) / \mathrm{cm}^{2} \cdot \mathrm{s} \cdot \mathrm{cmHg}$. 
Gas permeance in non-porous polymers is often related to the polymer fractional free volume (f) by [33-35]:

$$
\frac{P_{A}}{l}=A_{A} \exp \left(-\frac{B_{A}}{f}\right)
$$

where $A_{A}$ is a pre-exponential factor (GPU) and $B_{A}$ is a constant that increases with increasing penetrant molecule size $[34,36]$. The $f$ is usually estimated as follows:

$$
f=\frac{V-V_{o}}{V}
$$

where $V$ is the specific volume of the polymer at the temperature of interest, and $V_{o}$ is the specific occupied volume at $0 \mathrm{~K}$, which is estimated as 1.3 times the van der Waals volume [37]. The van der Waals volume can be estimated using Bondi's group contribution method [37].

Gas selectivity $\left(\alpha_{\mathrm{A} / \mathrm{B}}\right)$ is a ratio of their permeabilities or permeances, and is given by [32]:

$$
\alpha_{\mathrm{A} / \mathrm{B}}=\frac{P_{\mathrm{A}}}{P_{\mathrm{B}}}=\frac{P_{\mathrm{A}} / l}{P_{\mathrm{B}} / l}
$$

Combining Eqs. 2 and 4 gives

$$
\alpha_{A / B}=\frac{A_{A}}{A_{B}} \exp \left(\frac{B_{B}-B_{A}}{f}\right)
$$

When the gas component A has smaller molecule size than component B, Eq. 5 suggests that lower $f$ value leads to higher $\alpha_{\mathrm{A} / \mathrm{B}}$, since the $B_{A}$ value increases with increasing penetrant size [34,36]. 


\section{Experimental}

\subsection{Pretreatment of polyethersulfone support}

Flat sheet polyethersulfone ultrafiltration membrane (PES2) was purchased from Ultura ${ }^{\mathrm{TM}}$ High Recovery Membrane Technology (Long Beach, CA) and was used as the microporous support to prepare TFC membranes. The pores of the commercial PES2 support are filled with glycerol to preserve the porous structure. To prepare TFC membranes, the glycerol needs to be removed before the support is used, which is achieved using the following procedure. First, the support was soaked in deionized water and sonicated for 30 minutes. Second, the support was soaked in isopropyl alcohol (IPA) (VWR International, Radnor, PA) and sonicated for 20 minutes to remove the remaining glycerol and exchange the water with IPA. Third, the support was soaked in iso-octane (VWR International) for $1 \mathrm{hr}$ to remove the IPA, before drying in the air. The iso-octane has lower surface tension than IPA or water and therefore, the drying in the air is expected to have minimal damage for the pore structure. After the pretreatment, PES2 support exhibits an $\mathrm{N}_{2}$ permeance of $\sim 100,000$ GPU and $\mathrm{H}_{2}$ permeance of $\sim 300,000$ GPU at a feed pressure of $30 \mathrm{psig}$, which is much higher than the TFC membranes prepared (as shown later), indicating that the porous support has negligible transport resistance for gas transport compared with TFC membranes.

\subsection{Preparation of TFC membranes}

Table 1 shows the chemical structure of the amorphous glassy perfluoropolymers investigated. Teflon ${ }^{\circledR}$ AF1600 was purchased from DuPont (Wilmington, DE). Hyflon ${ }^{\circledR}$ AD80 and Hyflon ${ }^{\circledR}$ AD40 were purchased from Solvay Specialty Polymers (West Deptford, NJ). The coating solutions were prepared using a solvent of Novec ${ }^{\mathrm{TM}} 7200$ (ethoxyl-nonafluorobutane, 
$\mathrm{C}_{4} \mathrm{~F}_{9} \mathrm{OC}_{2} \mathrm{H}_{5}$ ) purchased from $3 \mathrm{M}(\mathrm{St}$. Paul, $\mathrm{MN})$. The solution was filtered using PES filters with a pore size of $200 \mathrm{~nm}$. The membrane coating was obtained using an automatic drawdown machine (DP-8301, The Paul N. Gardner Company, Pompano Beach, FL) with wire-wound lab rods. The film thickness was controlled by the polymer concentration in the solutions and the wire size of the rods. After the coating, the TFC membranes were dried for 15 seconds with a heat gun before annealing in a vacuum oven at $80{ }^{\circ} \mathrm{C}$ for $2 \mathrm{hr}$ to remove the solvent. When the membranes were taken out of the oven for cooling, the time was set at zero to study physical aging behaviors. The oven temperature of $80{ }^{\circ} \mathrm{C}$ is slightly higher than the boiling temperature of Novec $7200\left(76{ }^{\circ} \mathrm{C}\right)$ to ensure the solvent removal. Schematic of the TFC membranes is shown in Fig 1.

\section{Table 1}

Chemical structures, $T_{g}$, fractional free volume $(f)$ and $\mathrm{CO}_{2} / \mathrm{CH}_{4}$ separation properties at $35{ }^{\circ} \mathrm{C}$ of the perfluoropolymers studied in this work [30].

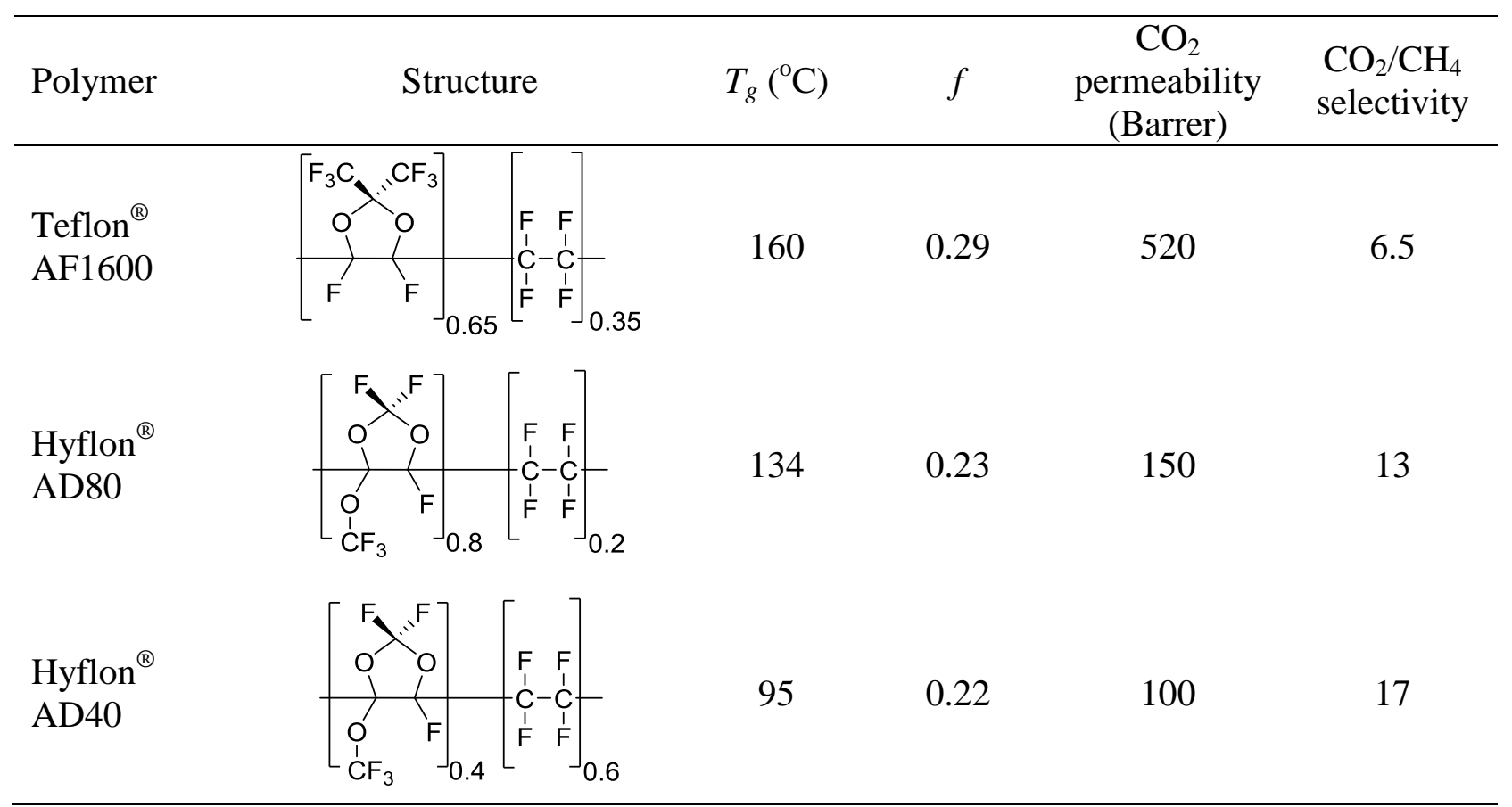




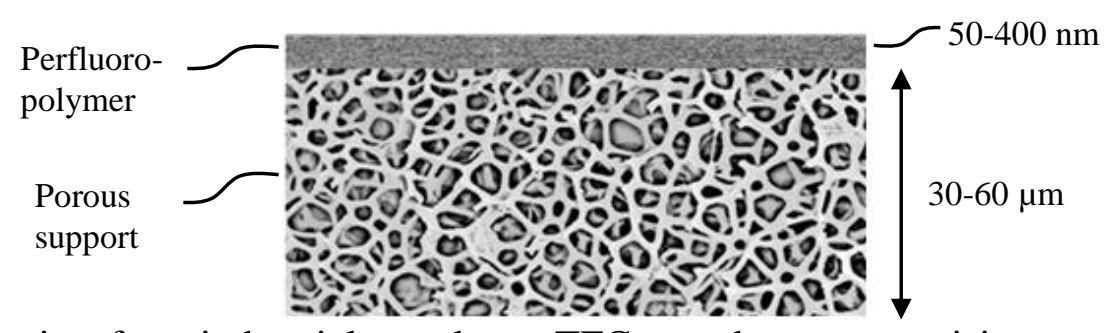

Fig. 1. Schematic of an industrial two-layer TFC membrane comprising a perfluoropolymer selective layer on top of a microporous support.

\subsection{Determination of pure gas permeance of TFC membranes}

Pure-gas permeances of $\mathrm{CH}_{4}, \mathrm{~N}_{2}, \mathrm{H}_{2}$, and $\mathrm{CO}_{2}$ of the TFC membranes were determined using a constant pressure/variable volume method at $35{ }^{\circ} \mathrm{C}$ [38]. Gas cylinders of $\mathrm{CH}_{4}, \mathrm{~N}_{2}$, and $\mathrm{H}_{2}$ with ultra-high purity and $\mathrm{CO}_{2}$ (with high purity) were obtained from Praxair Inc. (Buffalo, NY). The TFC membranes were masked using aluminum tape to avoid direct contact with the o-ring $[39,40]$. The masked membrane stamp was placed in a pressure filter holder (Millipore Corporation, Billerica, MA). Bubble flow meters were used to determine the gas flux through the TFC membranes, and the permeance can be calculated using Eq. 1.

TFC membranes were initially evaluated at feed pressures of 50, 100 and 150 psig using $\mathrm{CH}_{4}, \mathrm{~N}_{2}$ and $\mathrm{H}_{2}$ to verify that the membranes were defect-free. Pure-gas $\mathrm{CO}_{2}$ was tested at 50 psig to avoid the $\mathrm{CO}_{2}$ plasticization, which affects the aging behavior [12,41]. After testing, the TFC membranes were kept inside the permeation cell at room temperature in the air. The membranes were tested periodically using pure-gas $\mathrm{CH}_{4}, \mathrm{~N}_{2}$ and $\mathrm{H}_{2}$ at 50 psig and 100 psig and $\mathrm{CO}_{2}$ at 50 psig to monitor the effect of physical aging on gas transport properties.

\subsection{Determination of the selective layer thickness}

To determine the thickness of the perfluoropolymer selective layer, the TFC membranes were immersed in dimethylformamide (DMF, Sigma-Aldrich, St. Louis, MO) for 30 minutes to 
dissolve the PES support. The perfluoropolymers are not soluble in DMF and therefore, the thin films detached from the support and floated in the liquid, which were then transferred onto a silicon wafer. After drying in a vacuum oven at $80{ }^{\circ} \mathrm{C}$ for $2 \mathrm{hr}$, the film thickness was measured using a Filmetrics F20 thin-film measurement instrument (Filmetrics, Inc., San Diego, CA) $[42,43]$. The film thickness at different locations was measured and the variance is less than 5\%, indicating that the films have uniform thicknesses. The selective layer thickness can also be measured using Scanning Electron Microscope (SEM) to directly image membrane cross-section [43]. However, each SEM photo may only visualize small area of membrane samples, which is not as convenient as the Filmetrics F20 approach developed here for multi-spots measurements.

\section{Results and Discussion}

\subsection{Characterization of defect-free TFC membranes}

The TFC membranes were tested with pure-gases (including $\mathrm{CH}_{4}, \mathrm{~N}_{2}$ and $\mathrm{H}_{2}$ ) at various feed pressures after $1 \mathrm{hr}$ of aging to verify if they are defect-free before long-term aging study. Figs. $2 \mathrm{a}$ and $2 \mathrm{~b}$ exhibit gas permeances as a function of feed pressure at $35{ }^{\circ} \mathrm{C}$ in the membranes comprising Teflon AF1600 and Hyflon AD80, respectively. The membranes have a selective layer thickness of $100 \mathrm{~nm}$ and $180 \mathrm{~nm}$ for Teflon AF1600 and Hyflon AD80, respectively, which were determined using Filmetrics F20 after dissolving the support. The gas permeances are independent of feed pressures, indicating that these TFC membranes are defect-free $[32,44]$. The results for the membranes based on Hyflon AD40 are similar and they are presented in the Supplemental Information.

Fig. $2 \mathrm{c}$ and $2 \mathrm{~d}$ compare the pure-gas selectivity in the TFC membranes with that of bulk polymers reported in the literature [30]. In general, the TFC membranes exhibit selectivity 
values similar to or even higher than the freestanding films, which further corroborates that these TFC membranes are defect-free. The discrepancy in the selectivity may not be surprising since gas permeation properties in glassy polymers are often influenced by processing conditions, such as solvents used, thermal history and the film thickness [13,45]. For example, the TFC membranes in this study were prepared using a solvent of Novec 7200 , dried at $80{ }^{\circ} \mathrm{C}$ and have a selective layer thickness of less than $200 \mathrm{~nm}$. On the other hand, the freestanding films reported in the literature have a thickness of $15-150 \mu \mathrm{m}$, which were prepared using other fluorinated solvents and dried above their corresponding $T_{g}$ 's $[30,46]$.

(a)

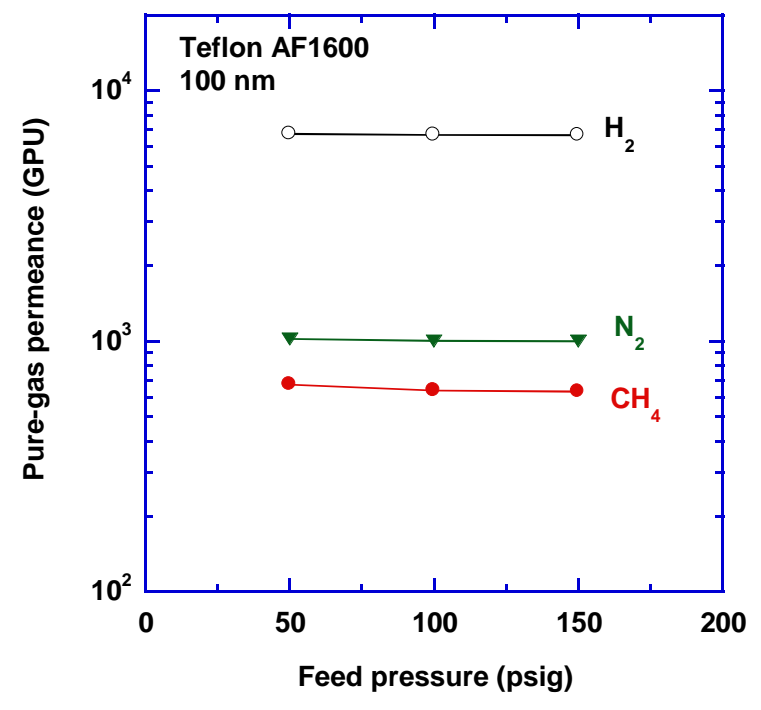

(b)

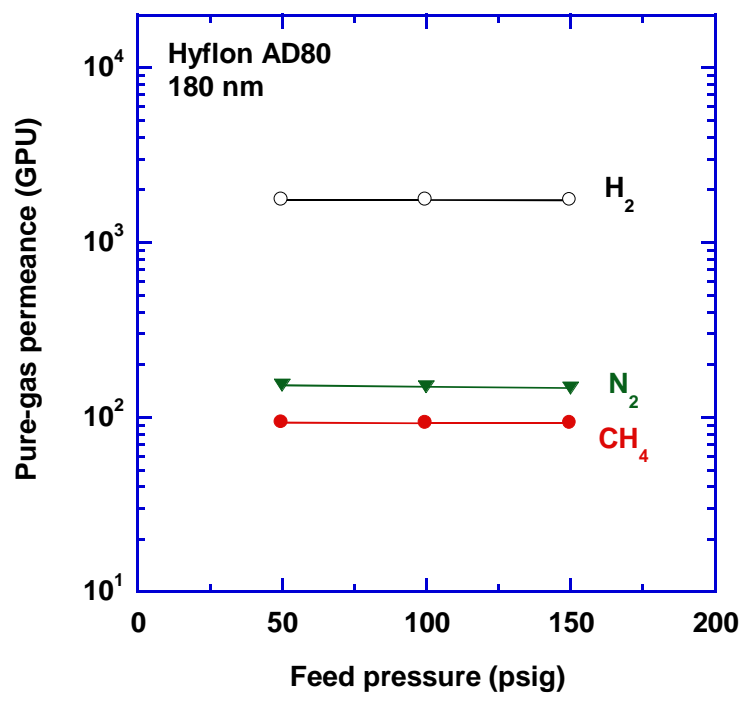


(c)

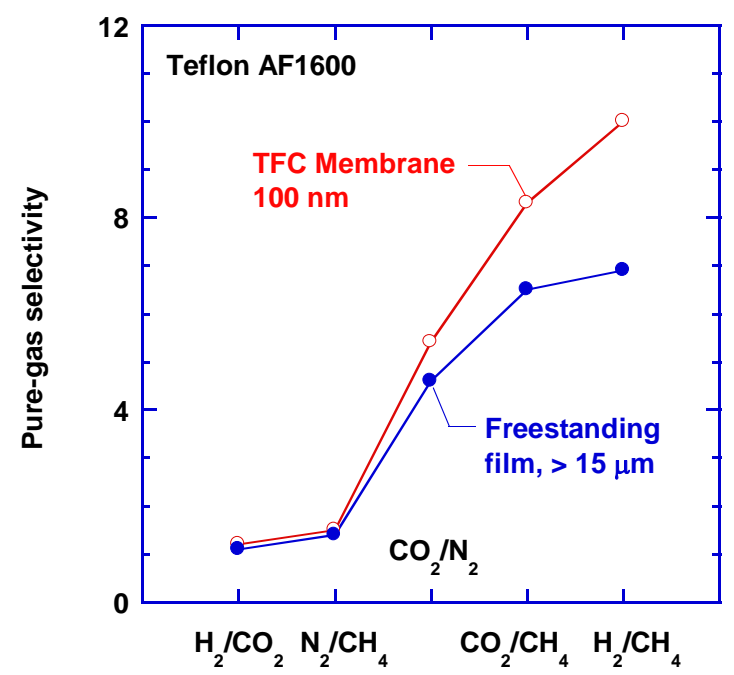

(d)

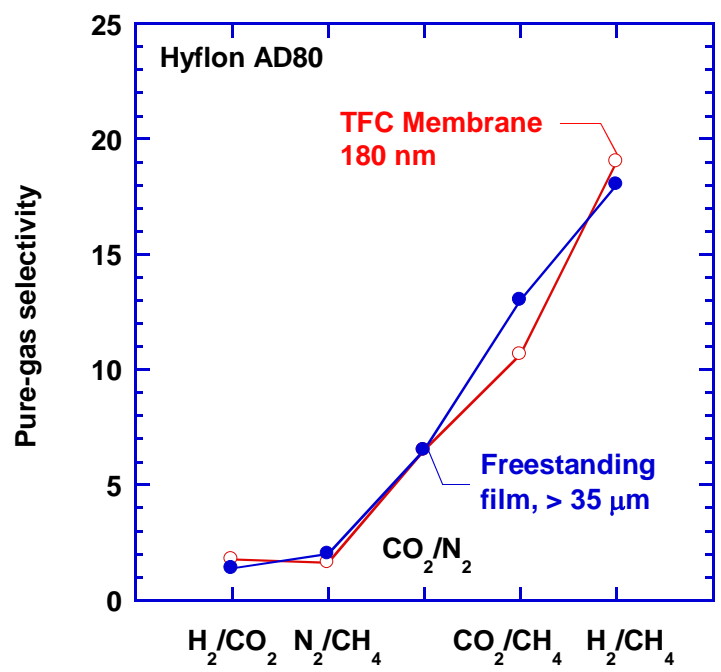

Fig. 2. Pure-gas permeances as a function of feed gas pressure at $35^{\circ} \mathrm{C}$ in TFC membranes comprising (a) 100-nm-thick Teflon AF1600 and (b) 180-nm-thick Hyflon AD80. Comparison of pure-gas selectivity of the TFC membranes comprising (c) Teflon AF1600 and (d) Hyflon AD80 with their corresponding freestanding films [30]. The TFC membranes aged for $1 \mathrm{hr}$ before the measurement.

\subsection{Effect of physical aging on gas permeances of TFC membranes}

Fig. 3 exhibits the pure-gas permeances of $\mathrm{CH}_{4}$ and $\mathrm{H}_{2}$ at $35{ }^{\circ} \mathrm{C}$ as a function of aging time in the TFC membranes comprising three perfluoropolymers (Teflon AF1600, Hyflon AD80 and Hyflon AD40) with varying selective layer thicknesses. Pure-gas $\mathrm{CO}_{2}$ and $\mathrm{N}_{2}$ show behaviors similar to $\mathrm{CH}_{4}$ and $\mathrm{H}_{2}$, and the results are presented in the Supplemental Information.

For the TFC membranes based on Teflon AF1600 and Hyflon AD80, four solutions with different polymer concentrations were used to prepare the membranes, including $2 \mathrm{wt} \%, 1 \mathrm{wt} \%$, $0.6 \mathrm{wt} \%$ and $0.3 \mathrm{wt} \%$. For the TFC membranes based on Hyflon AD40, two solutions with polymer content of $2 \mathrm{wt} \%$ and $1 \mathrm{wt} \%$ were used. Solutions containing less than $1 \%$ Hyflon AD40 cannot yield defect-free membranes, presumably because thinner layers are more susceptible to defects. In general, the thickness of the obtained selective layer increases with increasing polymer concentration in the coating solutions. For example, the Teflon AF1600 
solutions with polymer content of $2 \mathrm{wt} \%, 1 \mathrm{wt} \%, 0.6 \mathrm{wt} \%$ and $0.3 \mathrm{wt} \%$ yield the TFC membranes with the selective layer thickness of $370 \mathrm{~nm}, 175 \mathrm{~nm}, 100 \mathrm{~nm}$ and $50 \mathrm{~nm}$, respectively. The thickness of the obtained films varies slightly for different polymers even at the same solution composition, presumably due to the difference in the solution viscosity and density [47].

The measured permeance significantly differs from the ideal permeance, which is the ratio of gas permeability to the selective layer thickness. For example, with a selective layer thickness of $50 \mathrm{~nm}$, the TFC membrane based on Teflon AF1600 should have a $\mathrm{CH}_{4}$ permeance of 1600 GPU, while the measured $\mathrm{CH}_{4}$ permeance is only 1200 GPU. Such discrepancy has been ascribed to the geometric restriction from the porous support for the gas diffusion in the selective layer [48-51]. The low surface porosity of the porous PES support increases the length of the gas diffusion path in the selective layer and thus the gas permeance is significantly decreases. The details has been discussed elsewhere [52].

(a)

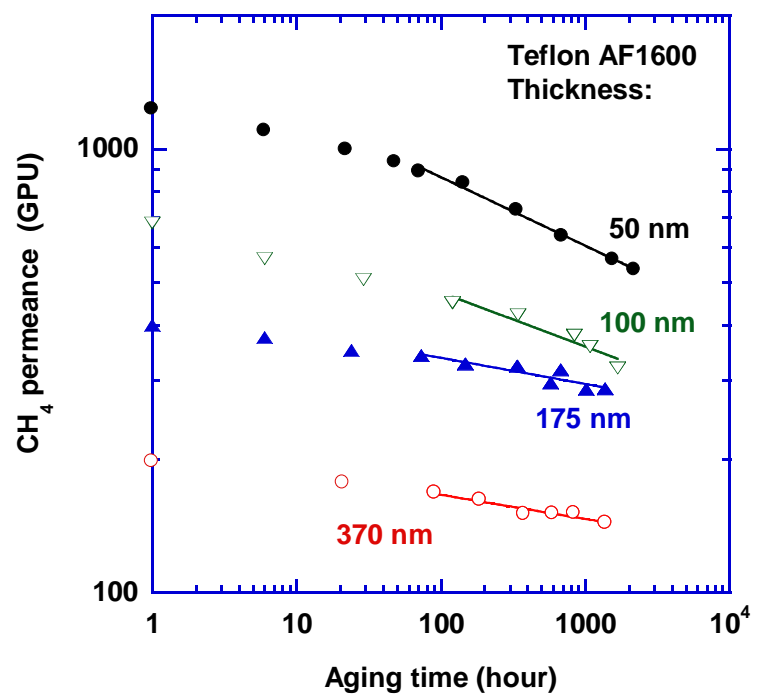

(b)

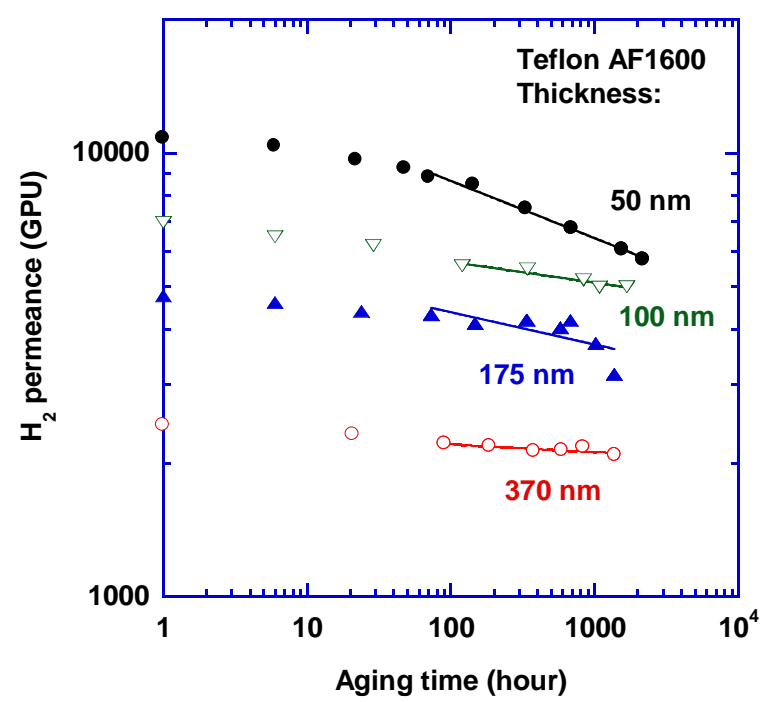


(c)

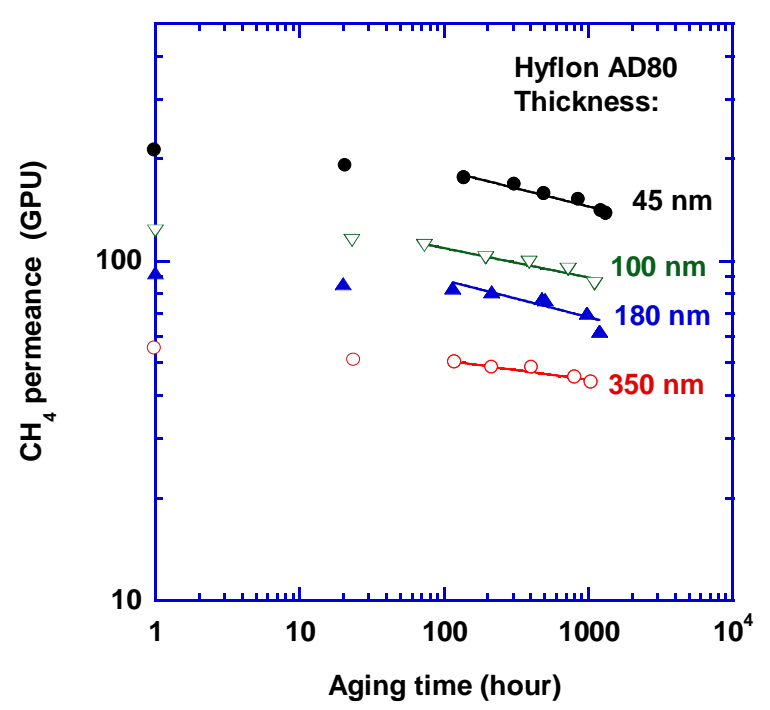

(e)

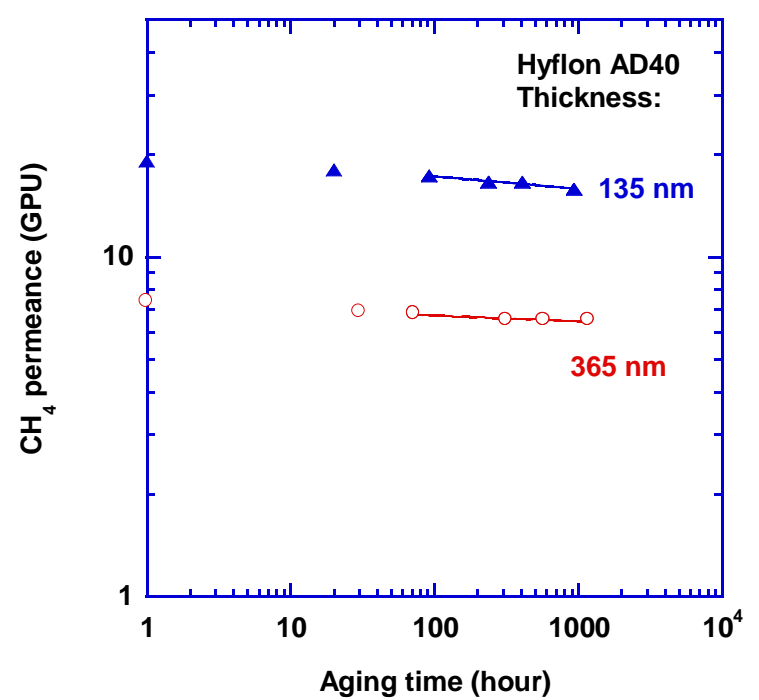

(d)

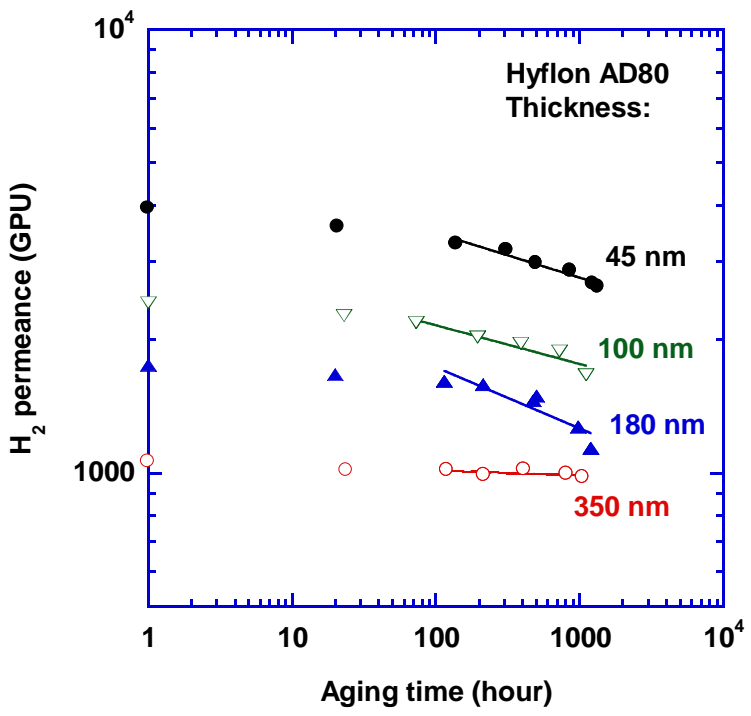

(f)

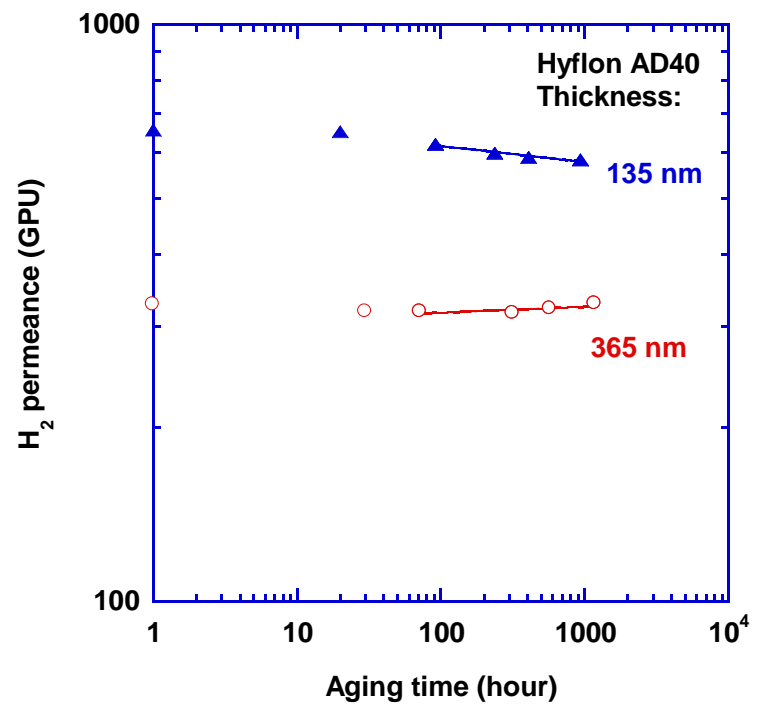

Fig. 3. Effect of the selective layer thickness and aging time on pure-gas permeances at $35{ }^{\circ} \mathrm{C}$ (in log-log plot) for (a) $\mathrm{CH}_{4}$ and (b) $\mathrm{H}_{2}$ in the Teflon AF1600-based TFC membranes; (c) $\mathrm{CH}_{4}$ and (d) $\mathrm{H}_{2}$ in the Hyflon AD80-based TFC membranes; and (e) $\mathrm{CH}_{4}$ and (f) $\mathrm{H}_{2}$ in the Hyflon AD40-based TFC membranes. The lines show the slope of $\log \left(P_{A} / l\right)$ versus $\log t$ after the membranes aged for $50 \mathrm{hr}$, which will be used to derive permeability reduction rate (cf. Eq. 7).

As shown in Fig. 3, gas permeances in all TFC membranes decrease with time, which is consistent with freestanding polymer films reported in the literature [10,53]. To quantitatively 
describe the change in permeances, a term of relative permeability or permeance $\left(\beta_{t}\right)$ at the aging time of $t(\mathrm{hr})$ is defined below as [53-55]:

$$
\beta_{t}=\frac{P_{t}}{P_{1 h}}=\frac{\left(p_{A} / l\right)_{t}}{\left(p_{A} / l\right)_{1 h}}
$$

where $\left(p_{A} / l\right)_{t}$ and $\left(p_{A} / l\right)_{1 h}$ are the gas permeance for component A after an aging time of $t$ and after $1 \mathrm{hr}$ of aging (i.e., the first permeance measurement in this study), respectively.

Fig. 4 presents the relative gas permeances of $\mathrm{CH}_{4}$ and $\mathrm{H}_{2}$ in the TFC membranes based on Teflon AF1600, Hyflon AD80 and Hyflon AD40. In general, the decrease in the relative gas permeance is more significant for thinner TFC membranes than thicker ones, because thinner films exhibit faster aging rate and thus more significant decrease in free volume. This behavior is also consistent with that in freestanding films $[6,7,10,13]$. However, there are several interesting observations as follows. First, for the TFC membranes based on Teflon AF1600, the permeance reduction is similar for those with thicknesses of $370 \mathrm{~nm}$ and $175 \mathrm{~nm}$, and for those with thicknesses of $100 \mathrm{~nm}$ and $50 \mathrm{~nm}$. This phenomenon has also been observed for the freestanding films of Teflon AF2400, where the permeability decrease follows two different behaviors for films with thickness below and above $1.6 \mu \mathrm{m}$ [13]. Second, the permeance reduction has a linear correlation with the logarithm of the time for the TFC membranes, except for those with the selective layer thickness of $\sim 50 \mathrm{~nm}$. For these ultrathin TFC membranes, the permeance reduction seems to accelerate with time. Third, the permeance reduction rate seems to follow the order below: Teflon AF1600 > Hyflon AD80 > Hyflon AD40. This order is also consistent with the order of decreasing $f$ and decreasing $T_{g}$, as shown in Table 1. The effect of $f$ and $T_{g}$ on physical aging and gas permeability will be discussed in the Part II of this study [56]. 
(a)

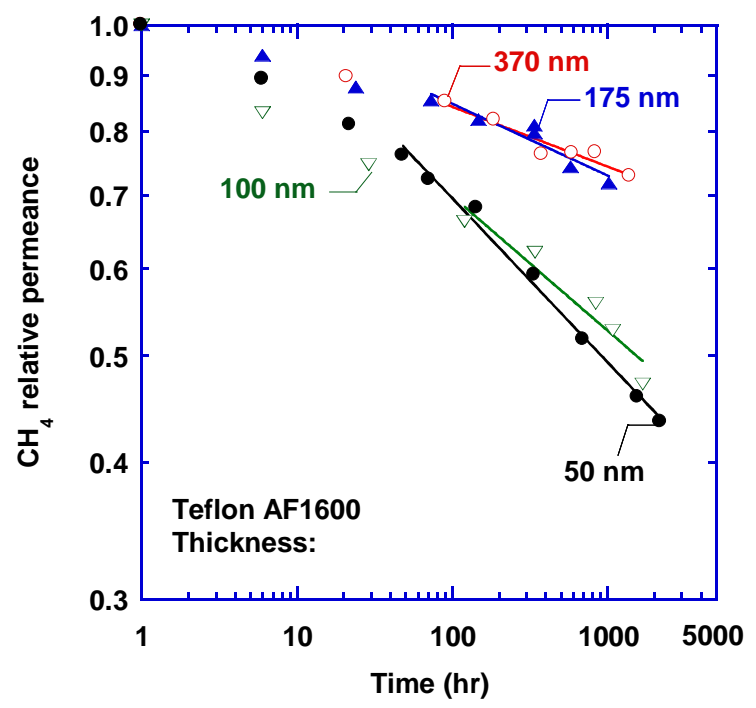

(c)

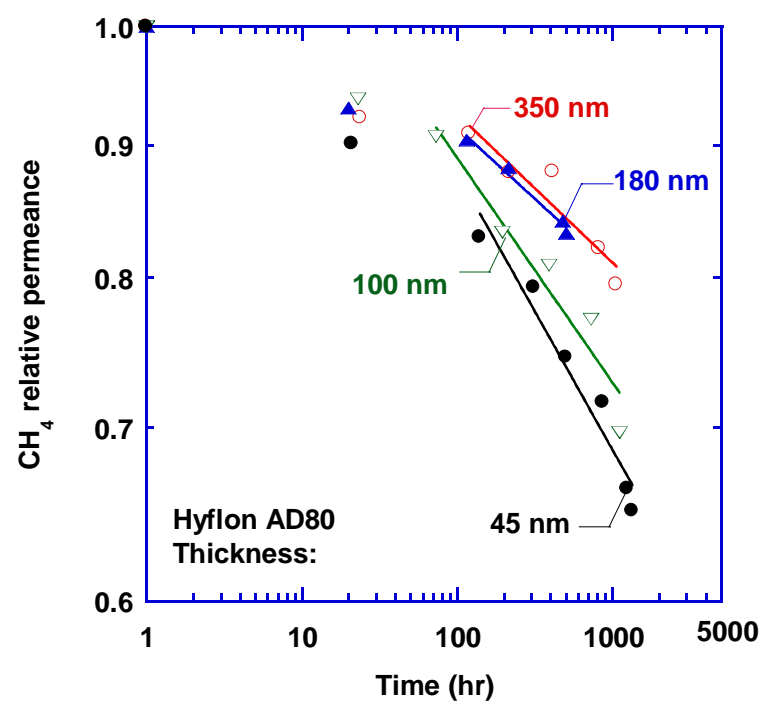

(b)

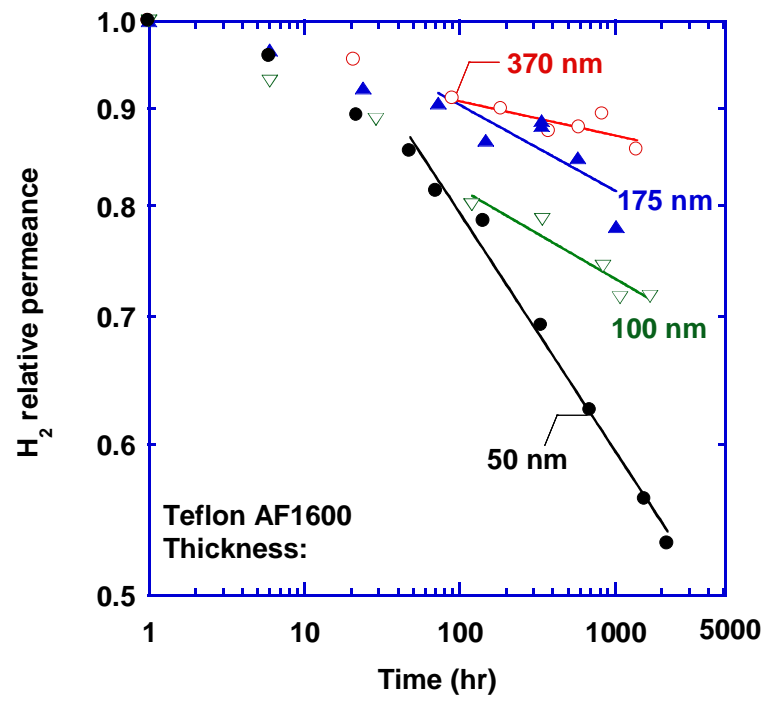

(d)

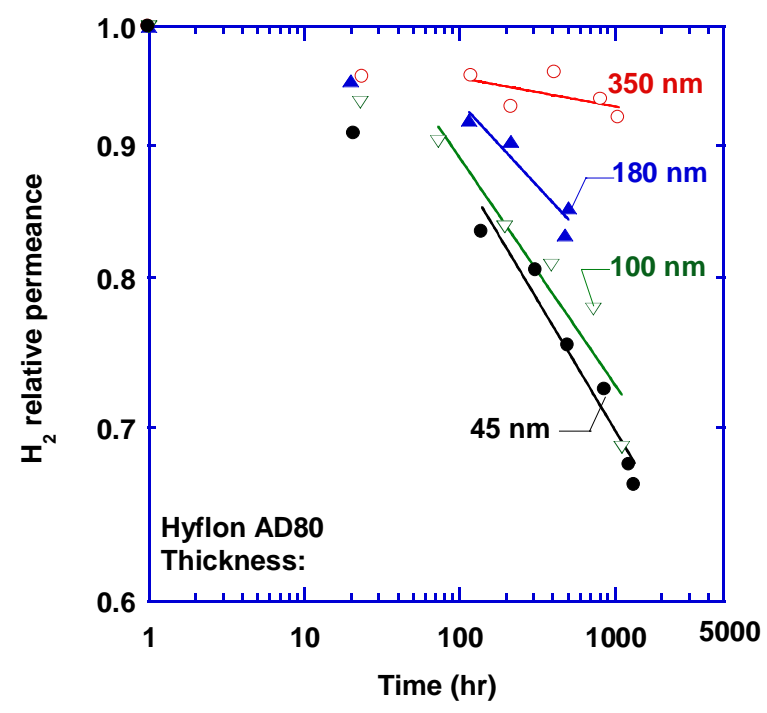


(e)

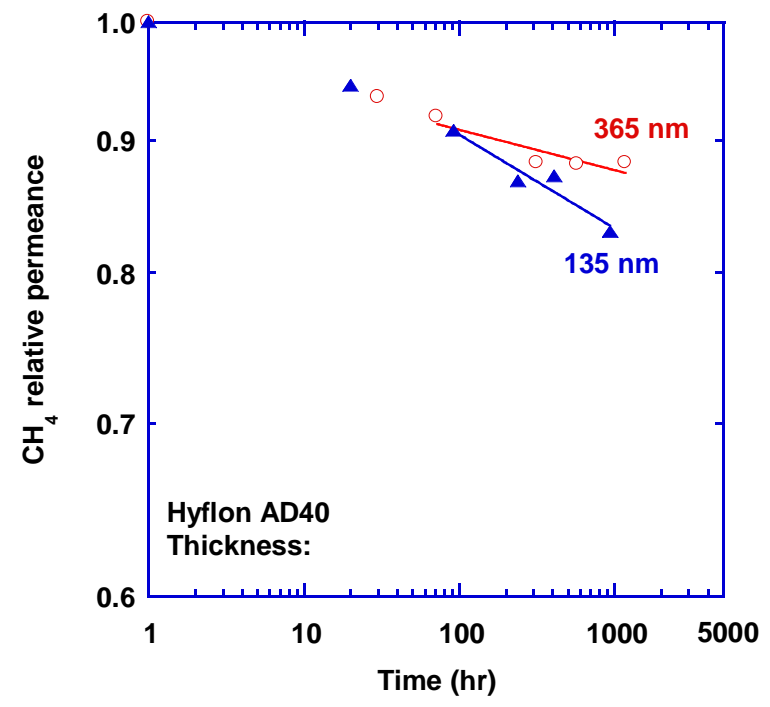

(f)

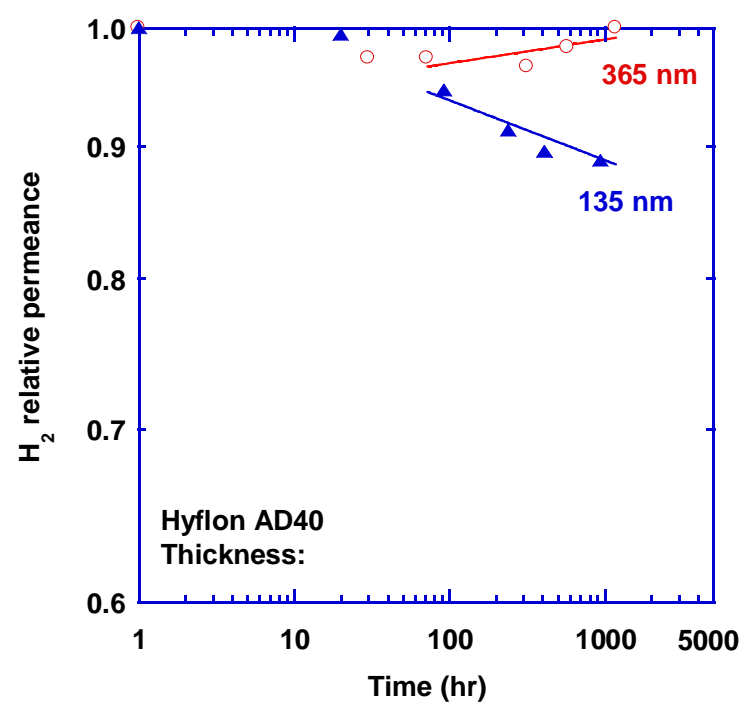

Fig. 4. Effect of the selective layer thickness and aging time on pure-gas relative permeance at $35^{\circ} \mathrm{C}$ for (a) $\mathrm{CH}_{4}$ and (b) $\mathrm{H}_{2}$ in the Teflon AF1600-based TFC membranes; (c) $\mathrm{CH}_{4}$ and (d) $\mathrm{H}_{2}$ in the Hyflon AD80-based TFC membranes; and (e) $\mathrm{CH}_{4}$ and (f) $\mathrm{H}_{2}$ in the Hyflon AD40-based TFC membranes. The lines show the slope of $\log \beta_{t}$ versus $\log t$ after the membranes aged for $50 \mathrm{hr}$.

Fig. 5 compares the relative permeance for $\mathrm{N}_{2}$ in three perfluoropolymer thin films, TFC membranes based on Teflon AF1600 (this study), freestanding thin films of Teflon AF1600 (UT film) [41], and TFC membranes based on perfluoropolymers (MTR TFCs) [28]. The reference permeance or permeability is at an aging time of $\sim 24 \mathrm{hr}$. Table 2 also summarizes the difference in the procedures and conditions in preparing these films or TFC membranes. 


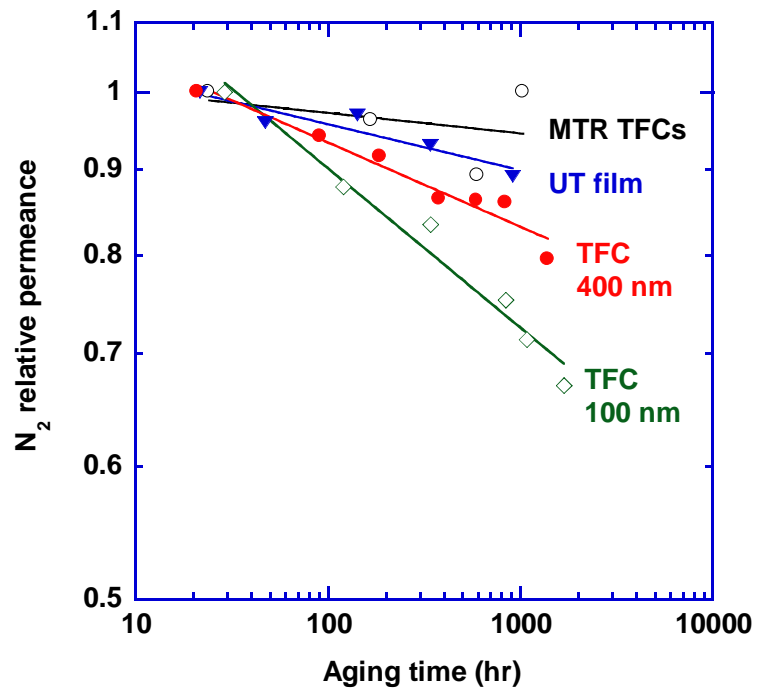

Fig. 5. Comparison of $\mathrm{N}_{2}$ relative permeance or permeability for Teflon AF1600 freestanding films with a thickness of $400 \mathrm{~nm}$ (UT film) [41], TFC membranes based on Teflon AF1600 (this study), and TFC membranes based on perfluoropolymers (MTR TFCs) [28]. The reference permeance/permeability is at an aging time of $\sim 24 \mathrm{hr}$.

\section{Table 2}

Comparison of the preparation procedures and conditions for freestanding Teflon AF1600 thin film (UT film) [41], TFC membranes comprising perfluoropolymers (MTR TFCs) [28], and TFC membranes comprising Teflon AF1600 (this study).

\begin{tabular}{|c|c|c|c|}
\hline $\begin{array}{l}\text { Membranes or } \\
\text { freestanding films }\end{array}$ & Support & $\begin{array}{l}\text { Preparation } \\
\text { method }\end{array}$ & $\begin{array}{l}\text { Thermal } \\
\text { treatment }\end{array}$ \\
\hline $\begin{array}{l}\text { UT freestanding } \\
\text { film [13] }\end{array}$ & $\begin{array}{l}\text { Anodisc } \\
\text { membranes }\end{array}$ & Spin coating & $\begin{array}{l}\text { Annealing } \\
\text { above } T_{g}\end{array}$ \\
\hline MTR TFCs [28] & $\begin{array}{l}\text { Poly(etherimide) } \\
\text { support }\end{array}$ & Dip coating & $\begin{array}{l}\text { Drying at } \sim 100{ }^{\circ} \mathrm{C} \\
\quad \text { for }<10 \text { mins }\end{array}$ \\
\hline TFCs (this work) & PES & Coating & $\begin{array}{c}2 \mathrm{hr} \text { in } 80^{\circ} \mathrm{C} \text { under } \\
\text { vacuum }\end{array}$ \\
\hline
\end{tabular}

The TFC membranes studied show aging behavior similar to the freestanding films. For example, after an aging time of about $900 \mathrm{hr}$, the TFC membranes with $370 \mathrm{~nm}$ selective layer show a relative $\mathrm{N}_{2}$ permeance of 0.86 , while the freestanding film with a thickness of $\sim 400 \mathrm{~nm}$ 
has the relative permeance of 0.89 . On the other hand, there seems to be significant difference in the aging behavior in the TFC membranes studied here and those studied at Membrane Technology and Research, Inc. (MTR) [28]. MTR produces the TFC membranes using industrial and lab scale coaters and the membranes show essentially no permeance reduction with time, even though the selective layer has a thickness of $83 \mathrm{~nm}[28,29]$. In comparison, the TFC membrane with a thickness of $100 \mathrm{~nm}$ in this study shows a relative permeance of only 0.80 after aging for $1400 \mathrm{hr}$. The reason is not clear, although a possible explanation could be the use of different apparatuses for preparing the TFC membranes and prior thermal history. MTR uses dip coaters with solution coating in vertical way and anneals membranes for only 10 mins at 100 ${ }^{\circ} \mathrm{C}$ [57], while this study uses a laboratory membrane coater with a horizontal coating and anneals membranes at $80{ }^{\circ} \mathrm{C}$ under vacuum for $2 \mathrm{hr}$. We do not expect the difference in the porous support could play an important role, since both poly(etherimide) and PES do not have specific interactions with perfluoropolymers.

\subsection{Effect of physical aging and film thickness on gas selectivity in TFC membranes}

Physical aging decreases polymer $f$ and thus increases gas selectivity with favorable diffusivity selectivity, such as $\mathrm{H}_{2} / \mathrm{CH}_{4}, \mathrm{H}_{2} / \mathrm{N}_{2}$ and $\mathrm{O}_{2} / \mathrm{N}_{2}$ separations, as indicated in Eq. $5[5,10]$. For example, Fig. 6 shows the pure-gas selectivity of $\mathrm{H}_{2} / \mathrm{CH}_{4}, \mathrm{H}_{2} / \mathrm{N}_{2}$ and $\mathrm{CO}_{2} / \mathrm{N}_{2}$ at $35^{\circ} \mathrm{C}$ in TFC membranes comprising Teflon AF1600 with various thicknesses. For all four TFCs, gas selectivity increases with aging time due to the decrease in free volume, which is also consistent with that in the freestanding films [13]. The TFC membrane comprising 50-nm-thick Teflon AF1600 film shows slightly lower selectivity than the others with thicker films. Thinner films are widely reported to have more flexible polymer chains (which may be indicated by lower $T_{g}$ ) 
[58,59], leading to weaker size sieving ability and lower selectivity. The TFC membranes comprising $100 \mathrm{~nm}, 175 \mathrm{~nm}$ and $375 \mathrm{~nm}$ selective layers seem to have very similar selectivity, especialy after $100 \mathrm{hr}$ aging. Similar behaviors have been observed for the TFCs comprising Hyflon AD40 and AD80 selective layers and the results are shown in the Supplemental Information.

(a)

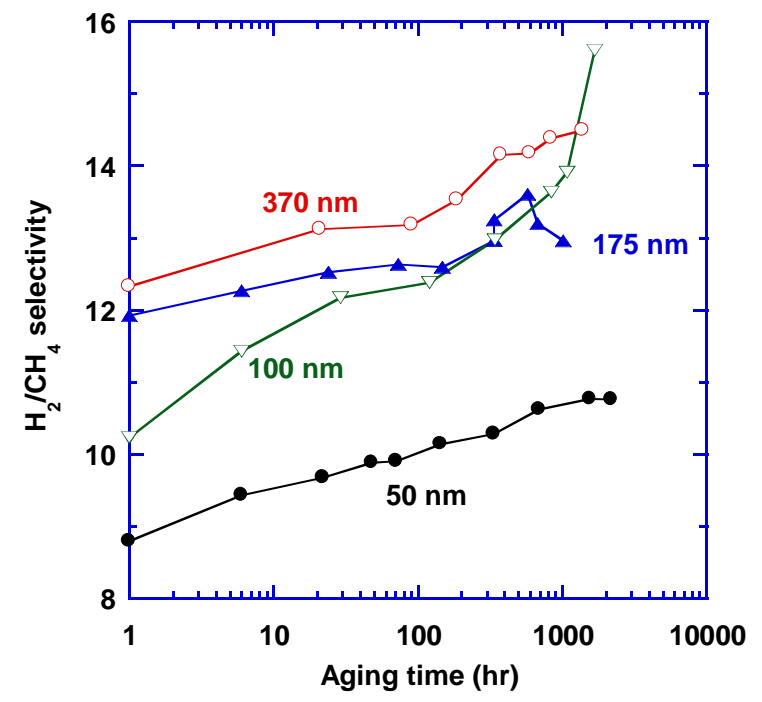

(b)

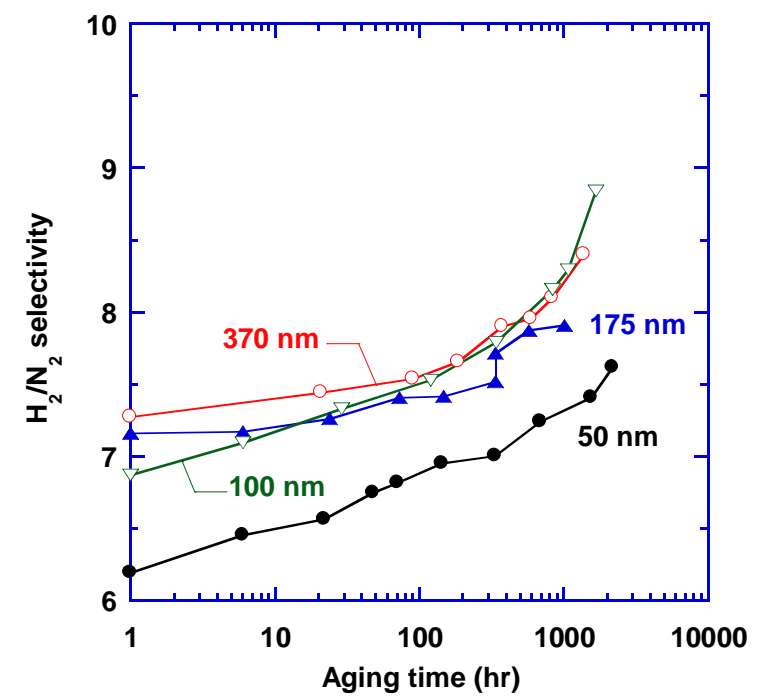

(c)

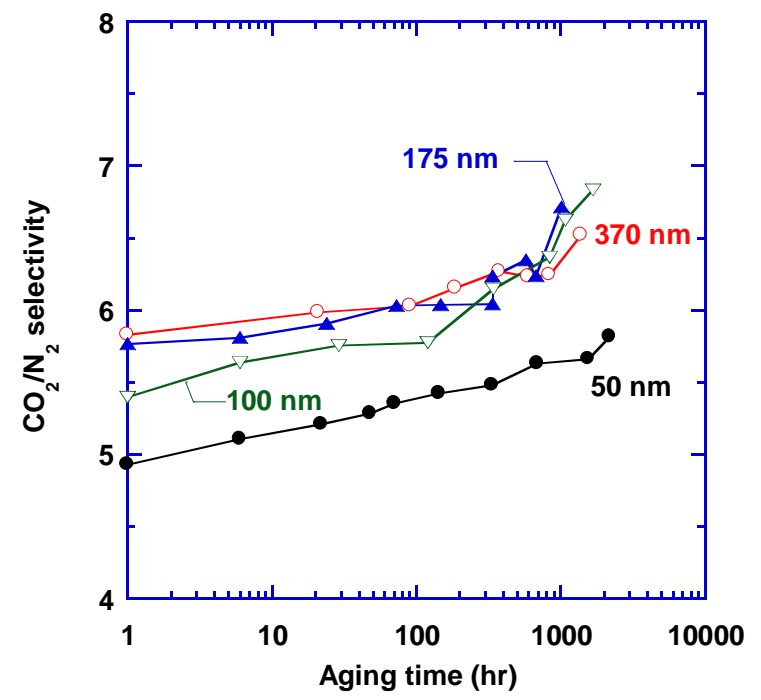

Fig. 6. Pure-gas selectivity of (a) $\mathrm{H}_{2} / \mathrm{CH}_{4}$, (b) $\mathrm{H}_{2} / \mathrm{N}_{2}$, and (c) $\mathrm{CO}_{2} / \mathrm{N}_{2}$ in the TFC membranes comprising Teflon AF1600 with various thicknesses at $35{ }^{\circ} \mathrm{C}$ and a feed pressure of $50 \mathrm{psig}$. 


\subsection{Effect of polymer structure and film thickness on the permeance reduction rate}

Fig. 7 depicts the comparison of relative gas permeance of $\mathrm{CH}_{4}$ and $\mathrm{H}_{2}$ at $1000 \mathrm{hr}\left(\beta_{1000 h}\right)$ for the TFCs based on Hyflon AD40, Hyflon AD80 and Teflon AF1600 at $35{ }^{\circ} \mathrm{C}$. The permeance reduction is greater for $\mathrm{CH}_{4}$ than for $\mathrm{H}_{2}$, since $\mathrm{CH}_{4}$ molecule (with a kinetic diameter of $3.8 \AA$ ) is larger than $\mathrm{H}_{2}$ with a kinetic diameter of $2.89 \AA$ [35]. As thin film polymer ages and free volume $(f)$ decreases [10], gas permeability decreases more rapidly for larger molecules with greater $B_{A}$ values (cf. Eq. 2).

(a)

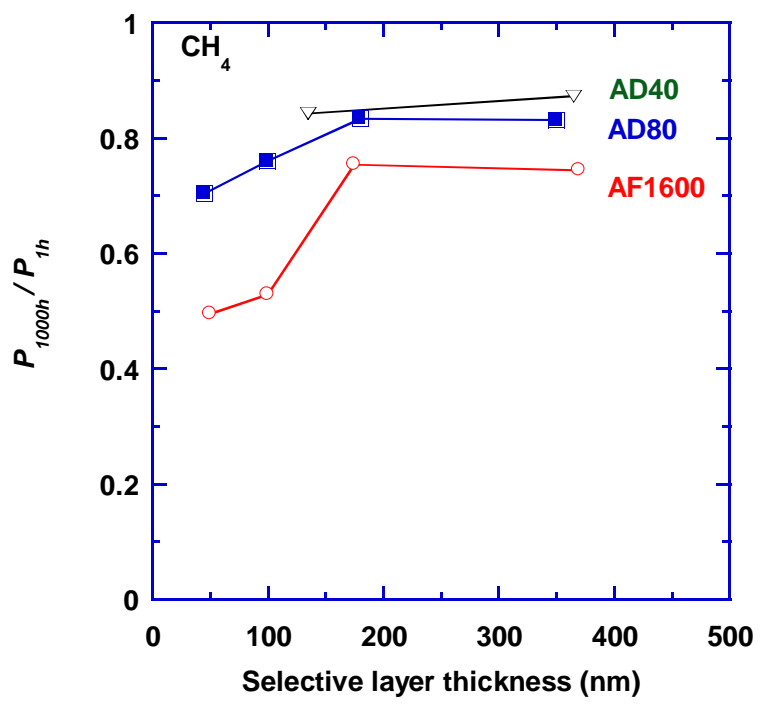

(b)

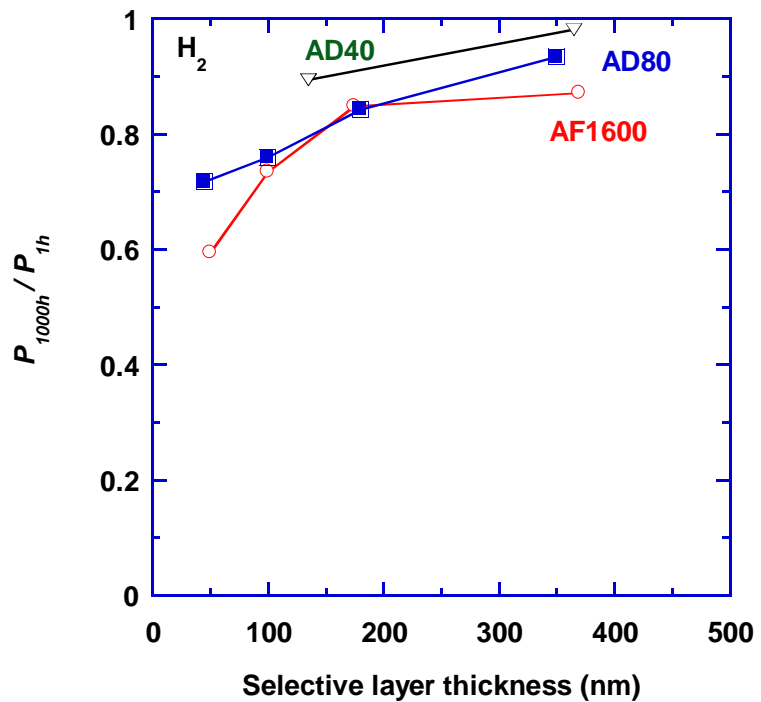

Fig. 7. Effect of polymer structure and film thickness on the permeance reduction $\left(\beta_{1000 h}\right)$ in the TFC membranes for (a) $\mathrm{CH}_{4}$ and (b) $\mathrm{H}_{2}$ at $35{ }^{\circ} \mathrm{C}$.

Fig. 7 shows that the $\beta_{1000 h}$ value decreases in the following order: Teflon AF1600 > Hyflon AD80 > Hyflon AD40. This order is independent of the selective layer thickness or gas type, and it is consistent with the order of decreasing $f$ or $T_{g}$, as shown in Table 1 . On the other hand, the order of the $\beta_{1000 h}$ value is different from the freestanding thin films. For example, freestanding thin films of Hyflon AD60 show greater decrease of the relative permeability than Teflon AF1600 [13]. 
The decrease of permeance with time for gas component A can be described using permeability reduction rate $\left(\gamma_{A}\right)$, which is given by $[10,13]$ :

$$
\gamma_{A}=-\frac{\partial \log P_{A}}{\partial \log t}=-\frac{\partial \ln P_{A}}{\partial \ln t}=-\frac{\partial \ln \left(P_{A} / l\right)}{\partial \ln t}=-\frac{\partial \ln \beta_{t}}{\partial \ln t}
$$

In this study, $\gamma_{A}$ is calculated based on the long-term aging data that show linearity between $\log P_{A}$ and $\log t$ [10], as shown in Fig. 3. Most of the TFC membranes show the linearity after aging for $50 \mathrm{hr}$.

Fig. 8 shows the $\gamma_{A}$ values of the TFC membranes and freestanding thin films for $\mathrm{CH}_{4}$ and $\mathrm{N}_{2}$. In general, the TFC membranes exhibit higher $\gamma_{A}$ values for thinner selective layers with higher free volume. Fig. 8 also compares the $\gamma_{A}$ values for the TFC membranes and a 400-nm-thick Teflon AF1600 freestanding film [13]. The TFC membrane shows higher $\gamma_{A}$ value than the freestanding film, presumably because the film preparation procedures have a significant effect on the physical aging behavior of glassy films.

(a)

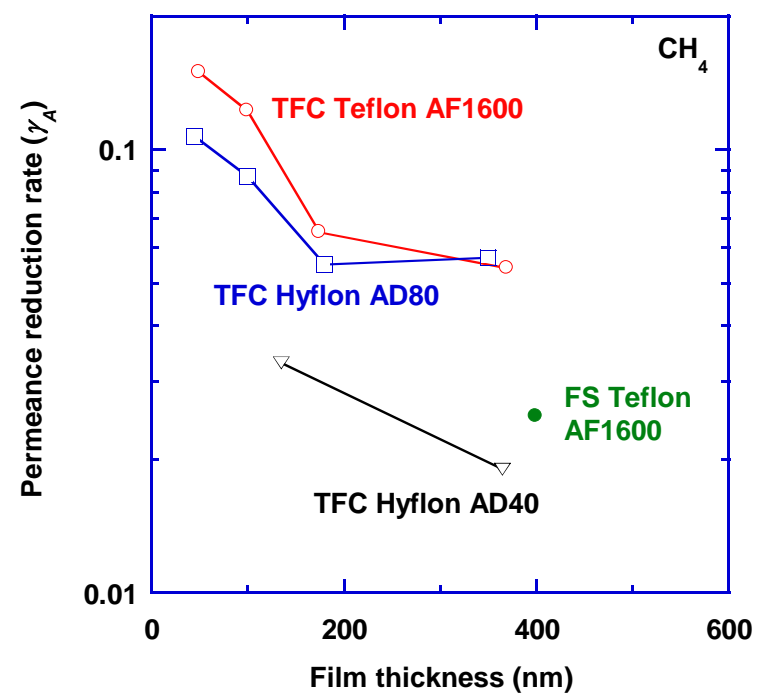

(b)

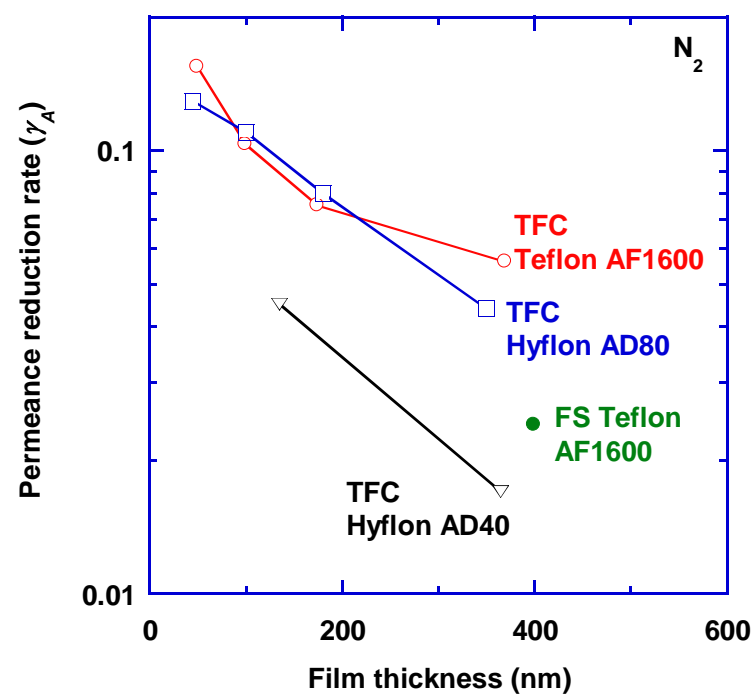

Fig. 8. Comparison of permeability reduction rate $\left(\gamma_{A}\right)$ of the TFC membranes and a freestanding Teflon AF1600 film (FS Teflon AF1600) [13] for (a) $\mathrm{CH}_{4}$ and (b) $\mathrm{N}_{2}$ at $35{ }^{\circ} \mathrm{C}$. 
The $\gamma_{A}$ values of glassy polymer films have been shown to depend on both $f$ and gas molecule size such as the squared kinetic diameter, $d_{e f f}^{2}[10]$. To verify if such correlation exists for the TFC membranes, Fig. 9 shows the correlation of the $\gamma_{A}$ and $d_{e f f}^{2}$ in the TFCs comprising a selective layer of $\sim 350 \mathrm{~nm}$. There is a linear correlation between the $\gamma_{A}$ and $d_{e f f}^{2}$, which can be explained below.

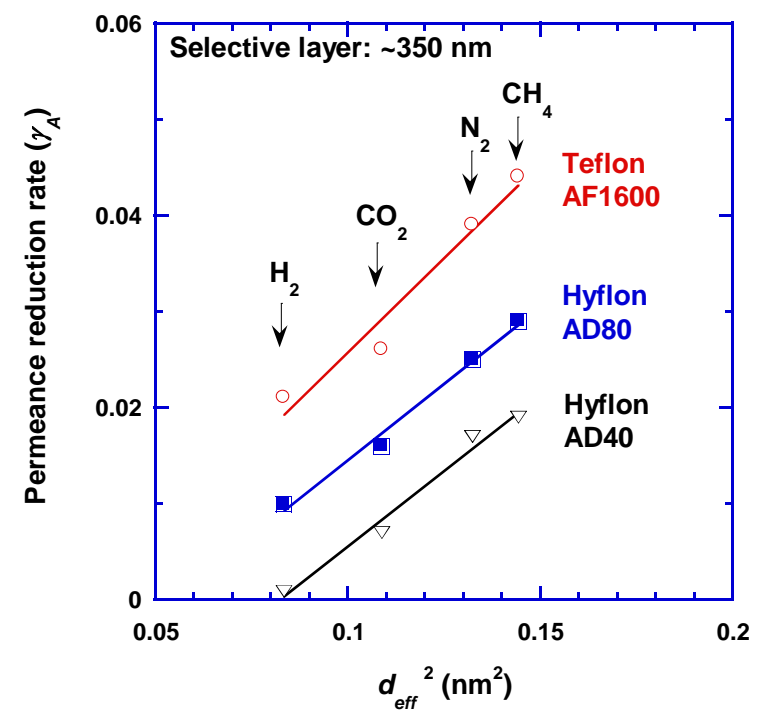

Fig. 9. Permeability reduction rate $\left(\gamma_{A}\right)$ in TFC membranes as a linear function of the squared kinetic diameter for gas molecules $\left(d_{\text {eff }}^{2}\right)$.

Combing Eqs. 3 and 7 gives the following expression [13]:

$\gamma_{A}=-\frac{\partial \ln P_{A}}{\partial \ln t}=B_{A} \frac{\partial(1 / f)}{\partial \ln t}$

The parameter $B_{A}$ can be related to $d_{e f f}^{2}$, indicating the minimal open area needed for gas molecular diffusion in the nonporous polymers, as shown in Eq. 9 [35,36].

$B_{A}=B_{0}+\kappa d_{A}^{2}$ 
where $B_{0}$ and $\kappa$ are adjustable constants, independent of penetrant size. Therefore, Eq. 8 can be rewritten as:

$\gamma_{A}=B_{0} \frac{\partial(1 / f)}{\partial \ln t}+\kappa \frac{\partial(1 / f)}{\partial \ln t} d_{A}^{2}$

The parameter of $\frac{\partial(1 / f)}{\partial \ln t}$ is polymer physical property and is independent of the penetrant sizes. Therefore, Eq. 10 clearly suggests that there is a linear correlation between the permeation reduction rate and $d_{\text {eff }}^{2}$ of penetrants.

\subsection{Comparison of $\beta_{1000 h}$ in perfluoropolymers and hydrocarbon polymers}

Fig. 10 compares $\mathrm{N}_{2}$ relative permeability at an aging time of $1000 \mathrm{hr}\left(\beta_{1000 \mathrm{~h}}\right)$ for glassy perfluoropolymers [41] and hydrocarbon polymers [25,53] as a function of their $f$ values. These films (in the freestanding form or TFC membranes) have a thickness of $\sim 400 \mathrm{~nm}$, except PTMSP (which has a thickness of $700 \mathrm{~nm}$ ). Hydrocarbon polymers exhibit a trend that higher $f$ values lead to lower $\beta_{1000 h}$ values. Presumably, higher $f$ values suggest greater excess volume relative to the equilibrium volume or higher driving force for polymer chains to relax, and thus greater aging rate. Interestingly, polystyrene (PS) exhibits much higher $\beta_{1000 h}$ value than other hydrocarbon polymers with similar free volume, which can be speculated as follows. Struik suggested that physical aging occurs below the polymer $T_{g}$, due to the movement of the polymer side chains, while the main chains are immobile in the time frame of gas diffusion [4]. Unlike other polymers with short side groups such as methyl groups, PS has bulky phenyl side groups and thus low mobility for chain relaxation. Consequently, PS exhibits a slower aging rate than other hydrocarbon polymers, though they may have similar free volumes or $T_{g}$. 
Perfluoropolymers exhibit much higher $\beta_{1000 h}$ values than hydrocarbon polymers with similar $f$ values. For example, both Teflon AF1600 and poly(1-trimethylsilyl-1-propyne) (PTMSP) have an $f$ value of 0.29 ; however, the $\beta_{1000 h}$ value is 0.78 and near zero for Teflon AF1600 (TFC membranes) and PTMSP, respectively. There are few studies aiming to understand the physical aging on a molecular level. We suspect that the side groups of perfluoropolymers containing $-\mathrm{CF}_{3}$ groups are much bulkier and heavier than their hydrocarbon analog $\left(-\mathrm{CH}_{3}\right)$. Consequently, the movement of the side groups (ascribed to the physical aging) is much slower for perfluoropolymers than hydrocarbon polymers, resulting in the slower aging rate in the perfluoropolymers.

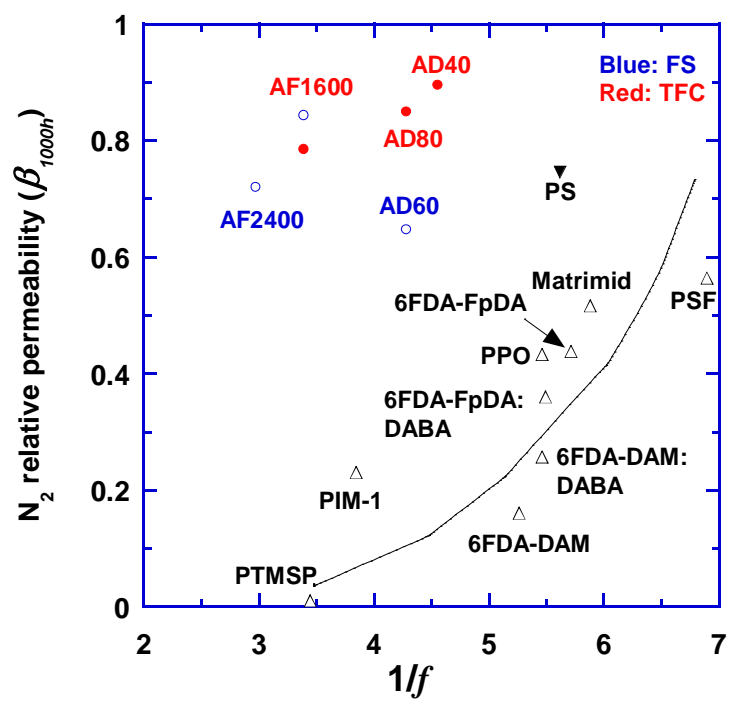

Fig. 10. Comparison of $\mathrm{N}_{2}$ relative permeability at $1000 \mathrm{hr}\left(\beta_{1000 \mathrm{~h}}\right)$ for perfluoropolymers $(\bullet$ : TFCs and $\circ$ : freestanding films or FS) and hydrocarbon polymers $(\Delta)$ [13]. PS ( $\mathbf{\nabla})$ : polystyrene; PSf: polysulfone; PPO: poly(phenylene oxide); polyimides: Matrimid, 6FDA-FpDA, 6FDAFpDA:DABA, 6FDA-DAM:DABA, 6FDA-DAM; PIM-1: polymer of intrinsic microporosity-1; PTMSP: poly(1-trimethylsilyl-1-propyne). 


\section{Conclusion}

The objective of this study (Part I and Part II) is to investigate the effect of physical aging of perfluoropolymer selective layers on gas permeance and selectivity in TFC membranes. In the present Part I study, two-layer TFC membranes consisting of perfluoropolymers at various thicknesses $(50-400 \mathrm{~nm})$ on a PES microporous support were successfully prepared and tested for pure-gas $\mathrm{CH}_{4}, \mathrm{~N}_{2}, \mathrm{H}_{2}$ and $\mathrm{CO}_{2}$ permeances at $35{ }^{\circ} \mathrm{C}$ for over $1000 \mathrm{hr}$. Pure-gas permeance decreases with time, and the decrease rate is more significant for larger penetrants, and for the TFCs with thinner selective layers. Physical aging increases pure-gas selectivity of $\mathrm{H}_{2} / \mathrm{CH}_{4}$, $\mathrm{CO}_{2} / \mathrm{CH}_{4}$ and $\mathrm{CO}_{2} / \mathrm{N}_{2}$. These behaviors are qualitatively consistent with those of freestanding films.

Among the three perfluoropolymers studied (i.e., Teflon AF1600, Hyflon AD80 and Hyflon AD40), permeability reduction rate $\left(\gamma_{A}\right)$ increases with increasing polymer fractional free volume $(f)$. The $\gamma_{A}$ values also increase linearly with the squared kinetic diameter of penetrants, which is experimentally validated and theoretically rationalized. These perfluoropolymers exhibit much higher $\beta_{1000 h}$ values than typical hydrocarbon polymers with similar $f$ values, which is hypothetically ascribed to the fact that the side groups (such as $-\mathrm{CF}_{3}$ ) in the perfluoropolymers are much bulkier and heavier than those (such as $-\mathrm{CH}_{3}$ ) in the hydrocarbon polymers to relax. Part II of the study will determine the glass transition temperature $\left(T_{g}\right)$ of the thin selective layers at various thicknesses and aging time in the TFC membranes, which will be used to correlate with the changes in $f$ and thus gas permeances. 


\section{Acknowledgments}

We gratefully acknowledge the financial support of this work from Korean Carbon Capture and Sequestration R\&D Center, and the partial support from the U.S. National Science Foundation under the award number 1554236. 


\section{References}

[1] R. W. Baker and B. Low, Gas separation membrane materials: a perspective, Macromolecules, 47 (2014) 6999-7013.

[2] D. F. Sanders, Z. P. Smith, R. Guo, L. M. Robeson, J. E. McGrath, D. R. Paul, and B. D. Freeman, Energy-efficient polymeric gas separation membranes for a sustainable future: A review, Polymer, 54 (2013) 4729-4761.

[3] W. J. Koros and R. P. Lively, Water and beyond: Expanding the spectrum of large-scale energy efficient separation processes, AIChE J., 58 (2012) 2624-2633.

[4] L. C. E. Struik, Physical Aging in Amorphous Polymers and Other Materials, Elsevier, New York, 1978.

[5] P. H. Pfromm and W. J. Koros, Accelerated physical aging of thin glassy polymer-films Evidence from gas-transport measurements, Polymer, 36 (1995) 2379-2387.

[6] Y. Huang and D. R. Paul, Physical aging of thin glassy polymer films monitored by gas permeability, Polymer, 45 (2004) 8377-8393.

[7] B. W. Rowe, B. D. Freeman, and D. R. Paul, Physical aging of ultrathin glassy polymer films tracked by gas permeability, Polymer, 50 (2009) 5565-5575.

[8] P. Gorgojo, S. Karan, H. C. Wong, M. F. Jimenez-Solomon, J. T. Cabral, and A. G. Livingston, Ultrathin polymer films with intrinsic microporosity: Anomalous solvent permeation and high flux membranes, Adv. Funct. Mater., 24 (2014) 4729-4737.

[9] H. Lin, Integrated membrane material and process development for gas separation, Curr. Opin. Chem. Eng., 4 (2014) 54-61.

[10] Y. Huang, X. Wang, and D. R. Paul, Physical aging of thin glassy polymer films: Free volume interpretation, J. Membr. Sci., 277 (2006) 219-229.

[11] W. H. Lin and T. S. Chung, Gas permeability, diffusivity, solubility, and aging characteristics of 6FDA-durene polyimide membranes, J. Membr. Sci., 186 (2001) 183-193.

[12] J. X. Zhou, A. T. Haldeman, E. H. Wagener, and S. M. Husson, $\mathrm{CO}_{2}$ plasticization and physical aging of perfluorocyclobutyl polymer selective layers, J. Membr. Sci., 454 (2014) 398-406.

[13] R. R. Tiwari, Z. P. Smith, H. Lin, B. D. Freeman, and D. R. Paul, Gas permeation in thin films of "high free-volume" glassy perfluoropolymers: Part I. Physical aging, Polymer, 55 (2014) 57885800.

[14] R. Swaidan, B. Ghanem, E. Litwiller, and I. Pinnau, Physical aging, plasticization and their effects on gas permeation in "rigid" polymers of intrinsic microporosity, Macromolecules, 48 (2015) 6553-6561.

[15] C. H. Lau, P. T. Nguyen, M. R. Hill, A. W. Thornton, K. Konstas, C. M. Doherty, R. J. Mulder, L. Bourgeois, A. C. Y. Liu, D. J. Sprouster, J. P. Sullivan, T. J. Bastow, A. J. Hill, D. L. Gin, and R. D. Noble, Ending aging in super glassy polymer membranes, Angew. Chem. Int. Ed., 53 (2014) 5322-5326.

[16] C. H. Lau, K. Konstas, A. W. Thornton, A. C. Liu, S. Mudie, D. F. Kennedy, S. C. Howard, A. J. Hill, and M. R. Hill, Gas-separation membranes loaded with porous aromatic frameworks that improve with age, Angew. Chem. Int. Ed., 54 (2015) 2669-2673.

[17] J. M. Hutchinson, Physical aging of polymers, Progr. Polym. Sci., 20 (1995) 703-760.

[18] K. D. Dorkenoo and P. H. Pfromm, Experimental evidence and theoretical analysis of physical aging in thin and thick amorphous glassy polymer films, J. Polym. Sci. Part B. Polym. Phys., 37 (1999) 2239-2251.

[19] J. E. Kluin, H. Moaddel, M. Y. Ruan, Z. Yu, A. M. Jamieson, R. Simha, and J. D. McGervey, Probe spectroscopy, free-volume concepts, and physical aging of polymer glasses, Adv. Chem. Ser., (1993) 535-555.

[20] B. W. Rowe, S. J. Pas, A. J. Hill, R. Suzuki, B. D. Freeman, and D. R. Paul, A variable energy positron annihilation lifetime spectroscopy study of physical aging in thin glassy polymer films, Polymer, 50 (2009) 6149-6156. 
[21] Y. Huang and D. R. Paul, Physical aging of thin glassy polymer films monitored by optical properties, Macromolecules, 39 (2006) 1554-1559.

[22] Y. P. Koh and S. L. Simon, Structural relaxation of stacked ultrathin polystyrene films, J. Polym. Sci. Part B. Polym. Phys., 46 (2008) 2741-2753.

[23] G. B. McKenna, Glass formation and glassy behavior, in C. Booth and C. Price (Eds.), Comprehensive Polymer Science: Vol. 2 Polymer Properties, Pergamon, Oxford, 1989.

[24] Y. Huang and D. R. Paul, Experimental methods for tracking physical aging of thin glassy polymer films by gas permeation, J. Membr. Sci., 244 (2004) 167-178.

[25] J. H. Kim, W. J. Koros, and D. R. Paul, Physical aging of thin 6FDA-based polyimide membranes containing carboxyl acid groups. Part II. Optical properties, Polymer, 47 (2006) 3104-3111.

[26] Y. Huang and D. R. Paul, Effect of molecular weight and temperature on physical aging of thin glassy poly(2,6-dimethyl-1,4-phenylene oxide) films, J. Polym. Sci. Part B. Polym. Phys., 45 (2007) 1390-1398.

[27] J. L. Keddie, R. A. L. Jones, and R. A. Cory, Interface and surface effects on the glass-transition temperature in thin polymer-films, Farad. Discuss., 98 (1994) 219-230.

[28] H. Lin, M. Zhou, J. Ly, J. Vu, J. G. Wijmans, T. C. Merkel, J. Jin, A. Haldeman, E. H. Wagener, and D. Rue, Membrane-based oxygen-enriched combustion, Ind. Eng. Chem. Res., 52 (2013) 10820-10834.

[29] Y. Okamoto, H. Zhang, F. Mikes, Y. Koike, Z. J. He, and T. C. Merkel, New perfluorodioxolane-based membranes for gas separations, J. Membr. Sci., 471 (2014) 412-419.

[30] T. C. Merkel, I. Pinnau, R. S. Prabhakar, and B. D. Freeman, Gas and vapor transport properties of perfluoropolymers, in B. D. Freeman, Y. P. Yampolskii and I. Pinnau (Eds.), Materials Science of Membranes for Gas and Vapor Separation, Wiley, 2006, pp. 251-270.

[31] Y. Huang, R. W. Baker, and J. G. Wijmans, Perfluoro-coated hydrophilic membranes with improved selectivity, Ind. Eng. Chem. Res., 52 (2013) 1141-1149.

[32] J. G. Wijmans and R. W. Baker, The solution-diffusion model: a review, J. Membr. Sci., 107 (1995) 1-21.

[33] M. H. Cohen and D. Turnbull, Molecular transport in liquids and glasses, J. Chem. Phys., 31 (1959) 1164-1169.

[34] J. K. Park and D. R. Paul, Correlation and prediction of gas permeability in glassy polymer membrane materials via a modified free volume based group contribution method, J. Membr. Sci., 125 (1997) 23-39.

[35] H. Lin, B. D. Freeman, S. Kalakkunnath, and D. S. Kalika, Effect of copolymer composition, temperature and carbon dioxide fugacity on pure- and mixed-gas permeability in poly(ethylene glycol)-based materials: free volume interpretation, J. Membr. Sci., 291 (2007) 131-139.

[36] H. Lin and M. Yavari, Upper bound of polymeric membranes for mixed-gas $\mathrm{CO}_{2} / \mathrm{CH}_{4}$ separations, J. Membr. Sci., 475 (2015) 101-109.

[37] D. W. Van Krevelen, Properties of Polymers: Their Correlation with Chemical Structure: Their Numerical Estimation and Prediction from Additive Group Contributions, Elsevier, Amsterdam, 1990.

[38] H. Lin and B. D. Freeman, Permeation and Diffusion, in H. Czichos, L. E. Smith and T. Saito (Eds.), Springer-Handbook of Materials Measurement Methods, Springer, 2006, pp. 371-387.

[39] H. Lin and B. D. Freeman, Gas solubility, diffusivity and permeability in poly(ethylene oxide), J. Membr. Sci., 239 (2004) 105-117.

[40] M. S. McCaig and D. R. Paul, Effect of film thickness on the changes in gas permeability of a glassy polyarylate due to physical aging Part I. Experimental observations, Polymer, 41 (2000) 629-637.

[41] R. R. Tiwari, Z. P. Smith, H. Lin, B. D. Freeman, and D. R. Paul, Gas permeation in thin films of "high free-volume" glassy perfluoropolymers: Part II. $\mathrm{CO}_{2}$ plasticization and sorption, Polymer, 61 (2015) 1-14. 
[42] H. Y. Lu, W. Chen, and T. P. Russell, Relaxation of thin films of polystyrene floating on ionic liquid surface, Macromolecules, 42 (2009) 9111-9117.

[43] L. Zhu, W. Jia, M. Kattula, K. Ponnuru, E. P. Furlani, and H. Lin, Effect of porous supports on the permeance of thin film composite membranes: Part I. Track-etched polycarbonate supports, In press, J. Membr. Sci., (2015).

[44] S. Matteucci, Y. Yampolskii, B. D. Freeman, and I. Pinnau, Transport of Gases and Vapors in Glassy and Rubbery Polymers, Materials Science of Membranes for Gas and Vapor Separation, John Wiley \& Sons, Ltd, 2006, pp. 1-47.

[45] M. Macchione, J. C. Jansen, G. Luca, E. Tocci, M. Longeri, and E. Drioli, Experimental analysis and simulation of the gas transport in dense Hyflon ${ }^{\circledR}$ AD60X membranes: Influence of residual solvent, Polymer, 48 (2007) 2619-2635.

[46] A. Y. Alentiev, V. P. Shantarovich, T. C. Merkel, V. I. Bondar, B. D. Freeman, and Y. P. Yampolskii, Gas and vapor sorption, permeation, and diffusion in glassy amorphous Teflon AF1600, Macromolecules, 35 (2002) 9513-9522.

[47] D. B. Hall, P. Underhill, and J. M. Torkelson, Spin coating of thin and ultrathin polymer films, Polym. Eng. Sci., 38 (1998) 2039-2045.

[48] H. K. Lonsdale, R. L. Riley, C. R. Lyons, and D. P. Carosella, Transport in composite reverse osmosis membranes, in M. Bier (Ed.), Membrane Processes in Industry and Biomedicine, Plenum Press, New York, 1971, pp. 101-122.

[49] G. Z. Ramon, M. C. Y. Wong, and E. M. V. Hoek, Transport through composite membrane, Part 1: Is there an optimal support membrane?, J. Membr. Sci., 415 (2012) 298-305.

[50] J. G. Wijmans and P. J. Hao, Influence of the porous support on diffusion in composite membranes, J. Membr. Sci., 494 (2015) 78-85.

[51] M. Kattula, K. Ponnuru, L. Zhu, W. Jia, H. Lin, and E. P. Furlani, Designing ultrathin film composite membranes: the impact of gutter layer, Sci. Rep., 5 (2015) 15016.

[52] L. Zhu, M. Yavari, W. Jia, E. P. Furlani, and H. Lin, Effect of porous supports on the permeances of thin film composite membranes: Part II. Industrial polyethersulfone supports, Submitted.

[53] Y. Huang and D. R. Paul, Effect of film thickness on the gas-permeation characteristics of glassy polymer membranes, Ind. Eng. Chem. Res., 46 (2007) 2342-2347.

[54] T. M. Murphy, B. D. Freeman, and D. R. Paul, Physical aging of polystyrene films tracked by gas permeability, Polymer, 54 (2013) 873-880.

[55] K. D. Dorkenoo and P. H. Pfromm, Accelerated physical aging of thin poly[1-(trimethylsilyl)-1propyne] films, Macromolecules, 33 (2000) 3747-3751.

[56] M. Yavari, S. Maruf, Y. Ding, and H. Lin, Physical aging of glassy perfluoropolymers in thin film composite membranes. Part II. Glass transition temperature and the free volume model, Submitted.

[57] R. W. Baker, Membrane Technology and Applications, 3rd ed., John Wiley and Sons, Ltd., Chichester, UK, 2012.

[58] J. Mattsson, J. A. Forrest, and L. Börjesson, Quantifying glass transition behavior in ultrathin free-standing polymer films, Phys. Rev. E, 62 (2000) 5187-5200.

[59] K. Fukao, T. Terasawa, K. Nakamura, and D. Tahara, Heterogeneous and aging dynamics in single and stacked thin polymer films, in T. Kanaya (Ed.), Glass Transition, Dynamics and Heterogeneity of Polymer Thin Films, Advances in Polymer Science, Vol. 252, 2013, pp. 65-106. 